Session 2230

\title{
Learning Essays and the Reflective Learner: Supporting Reflection in Engineering Design Education
}

\author{
Jennifer Turns, Wendy Newstetter, Janet K. Allen, and Farrokh Mistree \\ Georgia Institute of Technology
}

\begin{abstract}
Learning engineering design requires more than simply having design experiences. Design experiences provide a context for students to practice design skills and an opportunity for students to learn deep lessons about the nature of engineering design. Reflection on the experiences is necessary in order to recognize and realize these lessons. Student questions like "Why do we have to do so much paperwork" and "When are we going to get to the real design work of building" indicate when students are not taking the time to understand the lessons that are afforded by the design experience. We believe that the writing of learning essays can help students expand and enhance the lessons that they are learning from design experiences and, as a result, we have been using them in our design classes for over ten years. Learning essays are short, structured compositions in which students explore the lessons they have learned from experiences. Because of student difficulties selecting topics, structuring the essays, and understanding the role of the activity, not all students benefit as they could. Additionally, the overhead associated with the submission, grading, distribution of help, and management of the activity in the classroom creates problems for both students and instructors. In response to these difficulties, we have designed and developed the Reflective Learner, an electronic environment that supports and facilitates the learning essay writing activity. Students write their essays in the environment. The environment keeps track of the essays as well as provide several forms of support designed to address the student problems. Instructors can define essay assignments and grade submitted essays in the environment. In this paper, we describe the environment and present some findings from a formative evaluation during the 1996-1997 academic year.
\end{abstract}

\section{THE ROLE OF REFLECTION AND LEARNING ESSAYS IN ENGINEERING DESIGN}

In commenting on the state of engineering education, Dixon recently warned "We often confuse experience with learning, or provide experience without education" and "Experience per se does nothing for designers - or anyone else - unless they learn something cognitive in the process" [1]. Experiences, in the case of engineering design education, provide a context for students to practice design skills and an opportunity for students to learn deep lessons about the nature of engineering design. Student questions like "Why do we have to do so much paperwork" and "When are we going to get to the real design work of building" indicate when students are not taking the time to understand the lessons that are afforded by the design experience. Studies of learning suggest that those students who spend time trying to answer such questions through explanation, abstraction or theorizing tend to perform better on transfer tests of skills and conceptual understanding [2-4]. Such reflection on experience is a cornerstone to many theories of learning from experience $[5,6]$ and is increasingly recognized as a characteristic of successful practitioners [7-9]. We are looking for ways to help students be more reflective about the engineering design experiences that we provide for them [10]. 
We are particularly interested in the learning of engineering design skills and concepts through complex design experiences. In our design class, ME3110: Creative Decisions and Design [11], student teams work through a structured design process in order to 1) design and build a complex mechanical artifact and 2) learn general lessons about doing engineering design, working in teams, and learning from experience. In such an environment, students, under pressure to get the work done, may develop a task focus rather than a learning focus [12]. They often forget about the overall learning goals of the class (i.e., learn how to work in a team) in the midst of the demands of the project. The learning essay is an activity we use to get students to step away from the details of their personal design experience and reflect on what they can learn from the experience.

A learning essay is a written composition in which students document observations about their design experiences, explore the implications of the observations, and then articulate what they have learned. We have been using this activity for over ten years. Student write these essays following the completion of each phase of the design process (e.g., the planning phase and the conceptual design phase). Some essays are exhilarating to read and really convey a sense of a student's struggle to understand the design lessons inherent in their experiences. Other essays are terse, full of platitudes, unrelated to the students personal experiences, and generally unconvincing. In working with the students to understand why the quality of the essays varies, we have identified several problems:

- Topic: Students have problems choosing a topic(s) for their learning essays. They are unfamiliar with this format of writing and they feel uncertain about what topics are appropriate.

- Structure: Students have problems knowing how to structure the essay. Although the faculty have traditionally described the activity to the students in the class and given them examples, the students still are uncertain about how to structure the essay.

- Role: Students do not always understand the role of the essay. Coming from an environment where most learning is measured by test scores and right/wrong answers, they have trouble understanding the value in writing about your learning.

- Management: Students (and teachers) find essay management to be cumbersome. The overhead associated with the activity includes keeping track of the assignments and their due dates, submitting the assignments, and reading and interpreting the grading and feedback.

In response to these issues, we have designed and built the Reflective Learner ${ }^{1}$. The reflective learner is an environment that provides comprehensive support for the learning essay activity. Our goal is to create an environment that students will want to use and one that will help them with their problems. In this paper we describe the environment and some results from a formative evaluation. Overall, we were more successful than we had anticipated in creating an environment that students perceive to be useful and providing support that enhances the students' abilities to perform the activity.

\footnotetext{
${ }^{1}$ The design of the Reflective Learner was a joint effort of the first and second paper authors, with input from the last two authors. The development and maintenance of the software has been the sole responsibility of the first author.
} 


\section{REFLECTIVE LEARNER}

The Reflective Learner ${ }^{2}$ is an environment designed to comprehensively support and facilitate all aspects of the learning essay activity. The Reflective Learner is based on an analysis of the learning and instructor tasks involved in the learning essay activity such as composing and editing essays, submitting essays, and grading essays. It is also based on an analysis of what makes the activity difficult for students such as determining the topic and the structure of a particular essay and understanding the role of the assignment in general. In the Reflective Learner, learners can verify due dates, write essays, submit essays for grading, review graded essays, and seek help. Instructors can grade essays and define essay assignments. Students can also receive support in identifying a topic and structuring the essays for a given essay assignment.

In Figure 1, we have diagrammed the overall architecture of the Reflective Learner. The functionality available in the Reflective Learner is organized into several workspaces, shown as shaded areas in the diagram. Learners have an essay management workspace and an essay editing workspace. They also have access to a help library and a library of previously written essays. Instructors have an activity management workspace as well an essay grading workspace, an assignment definition workspace, and workspaces for maintaining the registered users and online help. The system determines the user's status of learner or instructor based on a "login", and directs the user to the appropriate functionality automatically.

In the next three sections, we describe a Web implementation of the Reflective Learner. We chose to implement the architecture in the Web environment in order to take advantage of several features that the Web provides. These include universal availability, platform independence, single point data storage, and integratability with other classroom resources.

\subsection{Login and Registration}

All users must have a registered identifier (a "login") and must pass through a login screen. The system uses the login to determine whether a user is a "learner" or an "instructor" and to locate the appropriate data. In Figure 2, we show the login screen of the software as viewed through Netscape. When a currently registered user logs on to the system, the system automatically takes them to either the learner or instructor functionality depending on their authority level. On-line registration makes it possible for students to become registered for the system without support of the instructor. Instructors are registered when the system is configured for a particular class.

2 The Reflective Learner can be accessed through the server http://chmsr.isye.gatech.edu. The logins of "guest" and "researcher", neither with passwords, will permit exploration of the software for any class, from a learner and instructor perspective respectively. The class, "ME3110-Fall96-Mistree", was the context for the study in this paper. For information on the availability of the Reflective Learner, please contact Jennifer Turns at jennifer@isye.gatech.edu. 


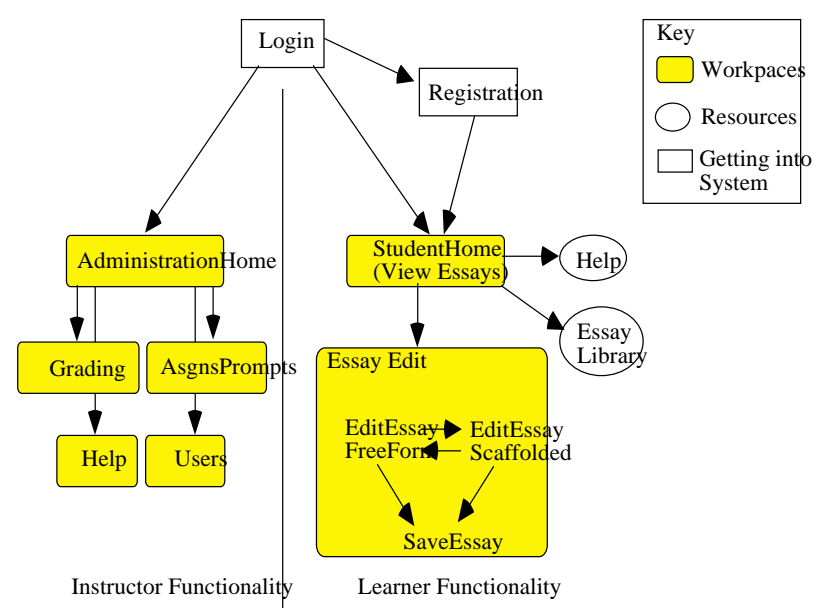

Figure 1. Architecture of the Reflective Learner

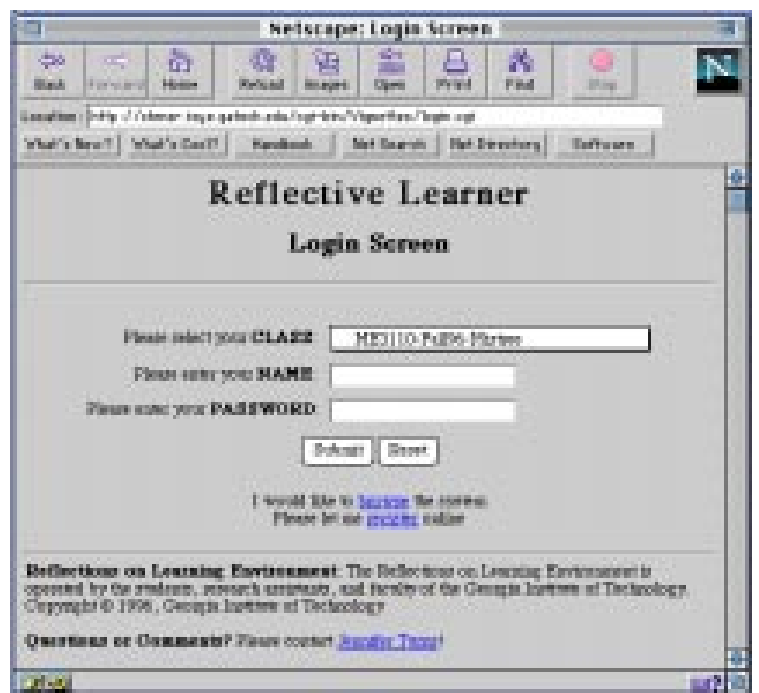

Figure 2. Reflective Learner Login Screen

\subsection{Learner Functionality}

A learner using the Reflective Learner has access to two workspaces, an essay editing workspace and an essay management workspace, as well as two resources, a library of prior essays and a library of help documents. The essay editing workspace, where learners write essays and receive support with the writing, is the heart of the system. Learners create and edit essays by simply typing into text windows (see Figure 3). The essay editing workspace consists of three areas: topic scaffolds, essay viewing and verification, and essay composition and editing.

- The topic scaffolds, at the top of the workspace, are suggested topics associated with a specific essay assignment. For example, a learner writing an essay following the public demonstration of the device might benefit from writing about what failures occurred and how these failures provide lessons about the types of contingencies for which designers should always be prepared. These topic scaffolds can be specific to particular essay assignment (e.g., the essay to be written after the public demonstration of the device) or general to all essay assignments being given in a class during a particular term (e.g., a scaffold about team issues might be appropriate over the entire term). The identification of these topics can come from many sources including an analysis of the types of problems that students have with a given design phase or the learning goals of the class.

- The essay composition and editing area is at the bottom of the workspace. Editing can be performed in either structure-scaffolded of unscaffolded mode. In the structure-scaffolded mode (shown at the bottom of Figure 3), the learner is presented with several editing areas each labeled as a component of the overall essay structure and containing a prompt for what generally should be covered. Since the learning essay is supposed to contain observations, explorations, and lessons, the suggested components of the essay relate to these three areas and the prompts describe what might be included in each component. The learner enters portions of the essay into each editing area, using the prompts as guides. In doing this, the student must keep in mind that their writings are not answers to questions but instead pieces of a holistic essay. Students can forego the structure scaffolding at any time, by choosing to edit in unscaffolded mode. In this case, the student simply types into a single text window. 
- Regardless of the mode used to edit the essay, the essay is displayed as a single continuous body of text. When the learner edits using the unscaffolded mode, this larger essay is simply the essay that they entered. When the learner edits using the scaffolded mode, the essay is the concatenation of the smaller units that they have typed. The viewing and verification area, in the center of the essay editing workspace, permits the learner to see the essay as it is saved in the system and as it appears once put together.

Learners reach the essay editing workspace, as well accomplish several other tasks, in the essay management workspace (see Figure 4). It is here that the system takes a student when they log in. At the top is a table from which the learner can verify due dates, control the submission of completed assignments, verify the grading status, and publish essays in the essay library (discussed further below). Below the table is a sequential list of all essay assignment titles along with the text of any essay that exists in the system. Links beside each essay title take the user to the essay editing workspace for that essay. The display format of the essay includes the title, keywords, grade, summary comments, and essay text. While learners can verify the overall essay grade in the table at the top of the workspace, they can look to the displayed essay for any summary comments or embedded comments. As more essays are written, the page grows in length. Because the essays on the page are organized chronologically, a learner who is editing later essays must scroll past earlier graded essays, perhaps stopping to inspect the grading of the previous essay before moving on to edit the next one due.

The Reflective Learner also provides two other forms of support for the learning essay activity. First, there is an extensive collection of help documents covering issues such as why the essays are important, how the essays are graded, and hints for effectively using the Reflective Learner. The second form of support is the essay library. Essays from previous quarters have been entered into the environment and indexed along several dimensions including design phase, central issue covered, and author. Learners wishing to simply read some old essays, both good and bad, can turn to the library. Additionally, learners can publish their essays in the library for

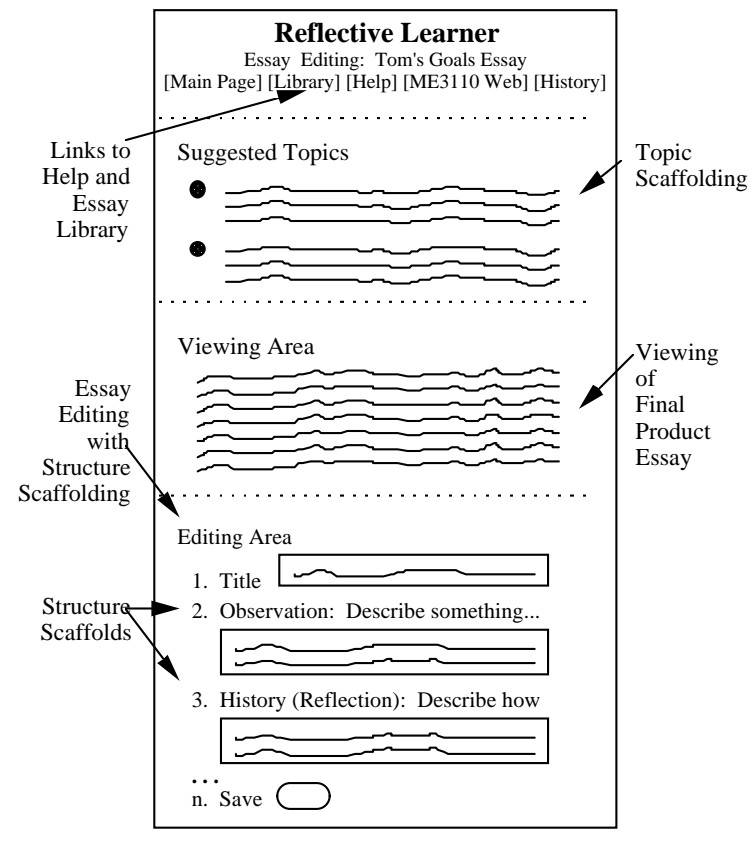

Figure 3. Essay Editing

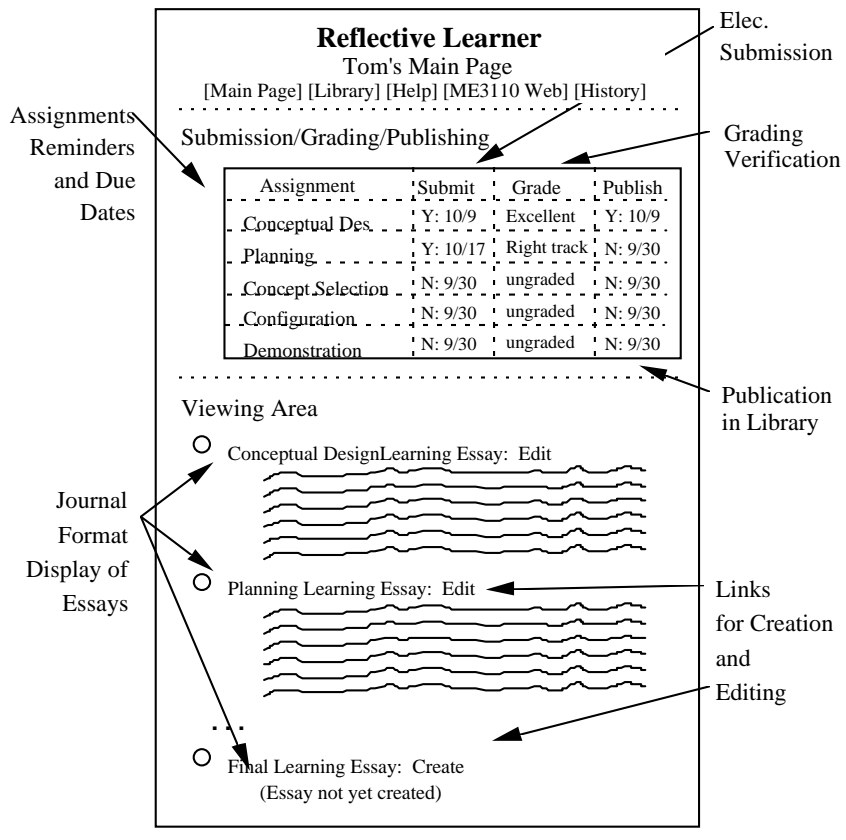

Figure 4. Learner "Main Page" 
sharing with other students in the class and for use by students in future quarters.

\subsection{Instructor Functionality}

Reflective Learner users with "instructor" status have access to five different workspaces. The activity management workspace (see Figure 5) provides overviews of much of the information in the system as well as navigation to the other four workspaces - the essay grading workspace, the assignment maintenance workspace, the user maintenance workspace, and the help maintenance workspace. The top of the activity management workspace consists of a table showing all the assignments and learners existing in the system. Learners' names show as hypertext links for each essay assignment that has been submitted electronically. Essays submitted electronically can be graded electronically and the link provides the navigation to the essay grading workspace (discussed more below).

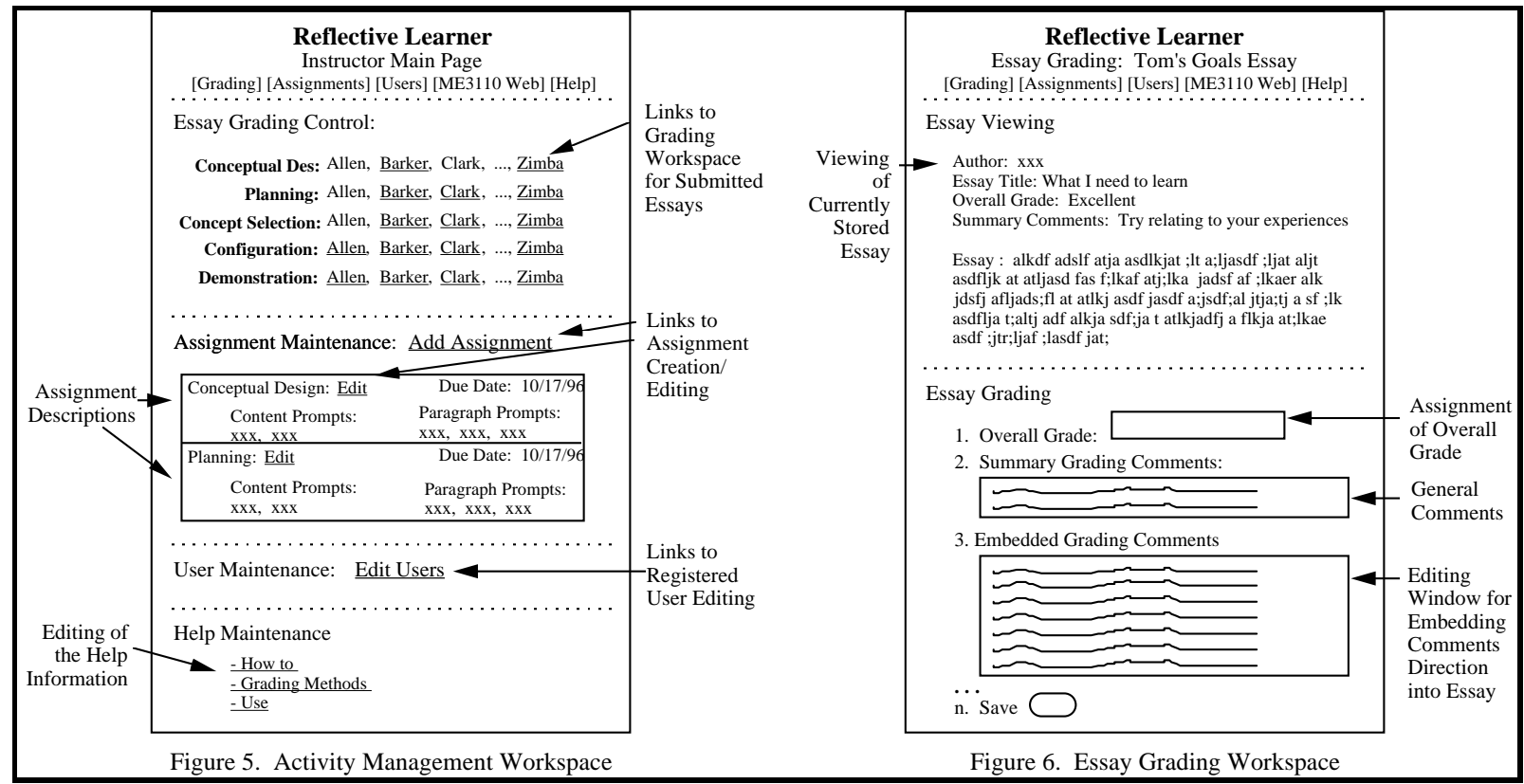

The next portion of the activity management workspace displays brief synopses of each essay assignment already defined and provides access to the assignment maintenance workspace, for the creation and editing of the assignments. An assignment is defined by the due date, topic scaffolds, and structure scaffolds which are associated with it. For example, suppose a teacher wishes his/her students to focus their post-planning learning essay on the uses of a written plan and also wishes the students to include in the essay, one example of how they have used a plan in the past. This instructor would add something about "uses of a written plan" to the list of topic scaffolds. The instructor would also add "Example: Describe a instance where you used a written plan" to the set of structure scaffolds.

The final part of the activity management workspace provides links to the user maintenance workspace and the help maintenance workspace. The user maintenance workspace provides a listing of all registered users for a class and makes it possible for the instructor to add, delete, or edit the information associated with the users. In the help maintenance workspace, a teacher can edit existing help documents, add new help documents, or delete help documents as appropriate. 
When an instructor follows the "grading" hypertext link associated with a student essay assignment in the grading table of the activity management workspace, the system will take him/her to the essay grading workspace populated with that essay (see Figure 6). The top of the workspace shows the essay in its display format, while the bottom of the workspace supports the actual grading. The Reflective Learner supports three forms of grading feedback - overall grade, summary comments, and embedded comments in the text. The instructor simply enters the grading information and presses save. The system will re-display the graded essay with the grading comments. Once satisfied with the grading, the instructor can return to the activity management workspace to select the next essay for grading. Grading comments are immediately available to students.

\section{Formative EvaluAtion: HYPOTHESES AND METHOD}

During the Fall, 1996 quarter we completed an initial formative evaluation of the Reflective Learner. In this evaluation, we were primarily interested in three issues associated with helping the students: how (and if) the students would perceive that the software was valuable, whether the features of the software would help address the identified student difficulties, and whether the essays would be better. In particular, we began with the following hypotheses.

- Perceived Usefulness Hypothesis: Students would find the Reflective Learner valuable. We expected that students who tried the system, would find it valuable and continue to use it.

- Features and Problems Hypothesis: The features of the Reflective Learner would help students address their problems. We had identified that students have problems with topics, structure, management, and understanding the role. These problems map almost one to one with the system features designed to address these problems - the topic scaffolds, the structure scaffolds, electronic submission, the essay and on-line help libraries. We believe that students make use of system features that they find helpful in addressing their problems, and thus we expected that they would use all the system features and that they would report these features as being valuable.

- Essay Quality Hypothesis: The quality of essays written within the Reflective Learner would surpass the quality of essays written outside of the Reflective Learner. We expected that student essays written within the Reflective Learner would be given higher grades, reflecting their higher quality.

To explore these hypotheses, we introduced the Reflective Learner software into Farrokh Mistree's section of our ME3110 design class during the Fall, 1996 quarter at Georgia Tech. The section consisted of twenty eight engineering students organized into five teams. The software was introduced to the students during the first week of the quarter. We gave a short presentation during a class period and a software demonstration later in the day. Throughout the quarter, the students were given complete freedom to choose if and when they would use the Reflective Learner for each of the ten assigned essays. Students were always free to write and submit the essays "conventionally". They were permitted to submit essays written in any manner, outside of the Reflective Learner, and turn them in during class. The two teaching assistants assigned to grade the students' work also graded the learning essays. The instructor of the class read the learning essays. The primary author of this paper sat through every lecture providing constant feedback to the students about the state of the environment and supporting them with any 
problems. She was also responsible for the task of customizing the topic and structure scaffolds throughout the quarter, based on activities ongoing in the class. Although both can be customized for each individual assignment, only the topic scaffolds were changed on a regular basis. The structure scaffolds remained the same for each assignment throughout the quarter.

In an effort to understand the impact of the tool on the students, we performed several types of evaluation activities. In addition to reading the submitted essays and observing the students in class, we also conducted two surveys, a focus group in the middle of the quarter, and exit interviews with ten of the twenty-eight students. As a result, we amassed several forms of data including copies of all graded essays (both essay submitted in the Reflective Learner and essays submitted conventionally), the results of the surveys, the transcripts of the interviews and focus group, and the trace of the students activity as recorded in logfiles. The findings reported below are based on what we have learned from this data so far.

\section{FINDINGS}

The use of the system and its impact on the students during the evaluation exceeded our expectations. The evaluations were overwhelmingly positive. In this section we report on the findings relative to each hypothesis.

\subsection{Perceived Value and Use Hypothesis}

One of our goals for the development of the software was to create an environment which students would perceive as useful. One way to measure the extent to which the students perceived it as useful is the number of students who used the system. In Table 1, we have shown the distribution of students using the Reflective Learner for each of the learning essay assignments over the duration of the term. We find three points interesting. First, over half of the essays submitted during the quarter were submitted electronically. Out of the 211 essays submitted, 115 were submitted electronically. This extensive level of use for voluntary software suggests that students found something about the software useful. Second, most students who tried the Reflective Learner on at least one essay, wrote several essays in the environment. Of the twenty

Table 1. Use of Reflective Learner for Essay Assignments

\begin{tabular}{|c|c|c|c|c|c|c|c|c|c|c|c|c|}
\hline$\overline{\text { Group }}$ & $|\overline{\text { Student }}|$ & & & $\bar{E}$ & $\mathrm{~S}$ & $\bar{S}$ & $\bar{A}$ & $\bar{Y}$ & & $\#$ & & \\
\hline & & $\overline{1}$ & 2 & 3 & 4 & 5 & 6 & 7 & 8 & 9 & 10 & Total \\
\hline & 1 & & & & & & & & & & & 0 \\
\hline 1 & 2 & & & & & & & & & & & 0 \\
\hline & 3 & & & & & & & & & & & 0 \\
\hline & $\begin{array}{l}4 \\
5\end{array}$ & & & & & & & & & & & 0 \\
\hline & 6 & & & & & & & 1 & 1 & & 1 & 2 \\
\hline 2 & 7 & & & & 1 & 1 & 1 & 1 & 1 & & 1 & 5 \\
\hline & 8 & & & & 1 & 1 & 1 & 1 & 1 & 1 & & 5 \\
\hline & 9 & & & & & & & & & & & 0 \\
\hline & 10 & 1 & & & & & & & & & & 1 \\
\hline & 11 & & & & & 1 & 1 & 1 & 1 & 1 & 1 & 5 \\
\hline & 12 & & & & & & & & & & & 0 \\
\hline 3 & 13 & 1 & & 1 & 1 & 1 & 1 & 1 & 1 & 1 & 1 & 8 \\
\hline & 14 & 1 & & 1 & 1 & 1 & 1 & & 1 & & 1 & 6 \\
\hline & 15 & 1 & & 1 & 1 & 1 & 1 & 1 & 1 & 1 & 1 & 8 \\
\hline & 16 & & & & 1 & 1 & 1 & 1 & 1 & 1 & 1 & 6 \\
\hline & 17 & 1 & 1 & 1 & 1 & 1 & 1 & 1 & 1 & 1 & 1 & 9 \\
\hline & 18 & & & 1 & 1 & 1 & 1 & 1 & 1 & 1 & & 6 \\
\hline 4 & 19 & & & 1 & 1 & 1 & 1 & 1 & & 1 & & 6 \\
\hline & 20 & & & 1 & 1 & 1 & 1 & & & & & 4 \\
\hline & 21 & & & 1 & 1 & 1 & 1 & & 1 & 1 & 1 & 6 \\
\hline & 22 & & & 1 & 1 & 1 & 1 & 1 & 1 & 1 & 1 & 7 \\
\hline & 23 & & & & 1 & 1 & 1 & 1 & 1 & 1 & 1 & 6 \\
\hline & 24 & & 1 & 1 & 1 & & & & & & 1 & 4 \\
\hline 5 & 25 & & 1 & 1 & 1 & 1 & & & 1 & 1 & 1 & 6 \\
\hline & 26 & & & 1 & 1 & 1 & 1 & 1 & & & 1 & 6 \\
\hline & 27 & 1 & 1 & 1 & 1 & 1 & 1 & 1 & 1 & 1 & 1 & 9 \\
\hline Total & In RL & 6 & 4 & 13 & 17 & 17 & 16 & $\overline{14}$ & 15 & $\overline{13}$ & 15 & 115 \\
\hline Total & Essays & 24 & 4 & 27 & 26 & 26 & 25 & 17 & $\overline{22}$ & $\mid \overline{13}$ & 27 & 211 \\
\hline
\end{tabular}


students who tried it, thirteen wrote more than half of the assigned essays in the environment and eighteen wrote four or more essays in the environment. Finally, there seemed to be a team culture effect surrounding the use of the software. Of the 7 students who never tried the software, 5 of these students constituted a single team.

It is interesting to compare the way the students came to use the system with what we had expected and embedded in our original evaluation plan. Through experience, we have found that getting students to make use of software resources available to them is often difficult $[12,13]$. In general, students are hesitant to try out new software because of the learning curve associated with the software and the difficulty in understanding what value will be provided by the software. In light of this, our original plan was to introduce the students to the software immediately at the beginning of the quarter, allow them with two weeks of voluntary use of the system, require all students to submit an essay through the Reflective Learner during the third week of the quarter, and finally to have students commit to one format for the remainder of the quarter and justify their preference. We believed that the mandatory electronic submission would move students past the learning curve obstacle, to where they could make the decision based on knowledge about the usefulness of the software. As it turned out, this precaution was not necessary. The Reflective Learner software was introduced to the students during a general session introducing the student to the software of the class. On the first essay submission, seven students out of 28 submitted electronically. By the second essay submission, the number submitting electronically had risen to fourteen (out of 28). Given that we were not having the difficulties we anticipated, we chose to leave the decision to use or not use the software in the hands of the students and they increasingly over the term chose to use it. We learned from this that it is possible to create software that students will voluntarily use to help them with their tasks.

\subsection{Features and Problems Hypothesis}

The level of use strongly suggests that students found the tool valuable. It is important, though, to know not only that they found the tool valuable but also to understand why they found it valuable. We had identified that students have problems with topics, structure, management, and understanding the role of the essays in the class. These problems map almost one to one with the features of the Reflective Learner designed to address these problems - the topic scaffolds, the paragraph scaffolds, electronic submission, the essay and on-line help libraries. We believe that students make use of system features that they find helpful in addressing their problems, and thus we hypothesized that they would use all the system features and that they would report these features as being valuable. We explored the hypothesis through three sets of data - the recorded use of features in the logfile, students responses to the mid quarter survey, statements from the mid quarter survey, and statements from the exit interviews. The rest of this section will focus on each of the five system features - structure scaffolding, topic scaffolding, electronic submission, and the essay and help libraries, what we learned about each feature, and whether the problems were overcome.

Structure scaffolding was very popular. This mode of editing is the most frequent mode as indicated by the logfile. On the survey, 15 out of 21 students agreed with the statement that the structure scaffolding was helpful. The students in the mid quarter focus group elaborated on the value of the structure scaffolding: 
- "It takes care of continuity, it helps you through your process,"

- “...having it ask for 'limitations' and 'other situations' was particularly useful to get me to think more constructively," and

- "Prompts got me to communicate and express my ideas in a more structured way."

Student comments on the value of the structure scaffolding also suggests the prompts helped them reconceive of the value of the learning essay:

- "Going through the scaffolding helped me to vent in a structured way," and

- "It helps me to take my learning to another level. Now I know I need to start early, [that I] need to answer questions like 'where can you apply', [it] causes you to think about how to apply [lessons] in other situations".

Students in the exit interviews claimed that the value of the structure scaffolding diminished over the quarter, as they became comfortable with the format of a learning essay. Some students suggested, though, the structure scaffolding prompts might have been valuable for a longer period if they had changed more frequently during the quarter.

The topic scaffolds were also very popular. While it is not possible to determine from the log files whether the students are using the topics scaffolds, the students reported both on the surveys and in the discussion groups that they were valuable. On the survey, 13 out of 21 students agreed with the statement that the topic scaffolding was helpful. In the mid-quarter focus group, a couple of students argued that the topic prompts were even more helpful than the structure prompts since they changed more frequently. The students suggested that the topic scaffolding was particularly useful when the instructor suggested a specific learning essay topic in class and they did not need to remember the topic since they later found it in the Reflective Learner. Unlike the findings with the structure scaffolds, the students in the exit interviews suggested that the continued to find the topic scaffolding valuable throughout the quarter. They also suggested that, while sometimes they knew what they wanted to write about prior to beginning the essay in the Reflective Learner, they often would go into the Reflective Learner unclear about what to focus on in their essay and then write about one of the suggested topics.

On-line submission emerged as critical feature in explaining the system's sustained usefulness for the students. Although it was possible for students to write essays within the environment but then print them and submit them in class, no student did this. During the exit interviews, several students suggested that while the scaffolding features were the reasons they started using the Reflective Learner, the electronic submission was the reason they continued using the Reflective Learner. These students unanimously agreed that submitting essays through the Reflective Learner was easier than doing it in the conventional manner.

From our perspective of encouraging true reflection on design activity, the electronic submission resulted in a unanticipated but very beneficial affordance - delayed submission of the essays. Learning essay assignments have always been tied directly to design assignments. In the past, students have submitted the learning essay with the design assignment. Because the students often do not finish the design assignments until very late on the night before the assignment is due (or even just before the class starts), the learning essays were often written when the student was very tired and not willing to commit much time to the activity. With the Reflective Learner in place, the learning essays did not need to be written and submitted with the report. Rather 
they simply needed to be in the environment by the time the teaching assistants were ready to grade them. Design assignments were submitted on Tuesdays and returned to the students on Thursdays. The teaching assistants made it known that they graded the assignments on Wednesday nights and that students could submit the learning essays up through Wednesday night. Thus, students were put in a position where they could step back from their design experiences, get a good night's rest, and then write their learning essay. It seems that a learning essay written under such circumstances would be more truly reflective than one written by tired students immediately upon completing a design activity. While we do not have evidence to prove that the essays were more reflective, the students did report more enjoyment of the activity and more perceived benefit when they could turn them in later.

The on-line help and essay libraries were almost never used, according the use of the software recorded in the logfile. Four students accessed the library a total of 30 times. Two students accessed the on-line help documents a total of 20 times. The appropriate inference seems to be that the help and the essay libraries were not perceived as valuable, and cannot be construed as helping students understand the role of the activity better.

Nevertheless, there is evidence that students using the Reflective Learner started to understand the role of the activity better than students not using the Reflective Learner. This evidence comes from the focus groups, exit interviews, and survey results. On the survey, 12 out of 21 students reported a sense of accomplishment at seeing their page grow as more essays were added. One student in the exit interviews claimed that it was "awesome to look back [at the journal format of essays] at the end of the quarter, and realize how much stuff you had learned". One question during the focus group was whether the learning essays were a waste of time. One student responded that they are ".. not a waste of time, they should be a separate class". Another student pointed out that the essays are important because the "lessons are anchored in the class". Finally, the students in the mid quarter focus group made some interesting comments about the role of the learning essay in helping them work through their frustrations (e.g., "using it was therapeutic" and "it helped me vent in a structured way") and also in helping them concretize lessons (e.g. "learning essays help make lessons concrete, causes you to take a step back, encourage deep enough thought to get them into your head"). Such findings suggest these students did see the writing of learning essays as serving a valuable role in the class.

\subsection{Essay Quality Hypothesis}

Evidence exists that the essays written in the Reflective Learner were better. In general, essays written in the Reflective Learner are more structured, have more specifics and examples, have fewer vague statements, and are longer. Grades on electronic essays were higher than grades on conventional essays consistently throughout the quarter, and were significantly higher for the only assignment analyzed statistically - the first graded essay. For this essay, 12 students submitted essays written within the Reflective Learner and 12 submitted them on paper. The mean score for the electronic essays was 8.23/10 while the mean score for the conventional essays was 7.23/10; based on a t-test, this difference statistically significant at the level $\mathrm{p}<0.05$.

We realize our comparison is fraught with many confounds, the students who use the software were self-selected, the graders of the essays were fully aware of the identity of the student and whether the essay had been written within the Reflective Learner, and the grading was performed 
in an ad-hoc manner. While these findings are suggestive, we certainly need to develop more standardized measures of essay quality and more controlled comparison situations.

\section{DisCUSSION AND FUTURE DIRECTIONS}

We are very excited about the state of this research effort. The response from the students and faculty have been overwhelmingly positive. We have built a tool that helps students overcome problems with and ultimately understand an activity designed to make them more reflective learners. In light of our research findings, we are making small modifications to the design of the system. Primarily, though, we are moving forward with various steps that will permit us to better understand the role of the reflective activity that we are asking students to do. Specifically, we are currently proceeding with the research on several fronts:

- Designing and performing content, quality, statistical, and linguistic analyses of the essays written and submitted during the Fall '96 quarter. By knowing the range of concepts covered, the quality measured relative to more formal standards, and the type of language students use in the essays, we believe we will better understand how the activity is impacting student learning.

- Exploring the broader impact of the learning essay assignment, particularly when supported by the Reflective Learner, on the class. The analysis in this paper focused on the impact of the Reflective Learner on the students' writing of the essays and understanding of the assignment. What other aspects of the class situation are impacted by the learning essays and the Reflective Learner? How can a teacher make use of learning essay information for assessment?

- Formalizing a model of learning essay activity based on cognitive science literature on learning from experience. Cognitive science research on learning from experience has found that reflective activities such as abstraction, self explanation, and indexing expand and enhance the lessons learned from experience. A conceptualization of the learning essay activity in terms of those literatures will help us create hypotheses about the measurable impact of the activity on learning.

- Designing mini-experiments to determine the role that the writing of the learning essay has in learning from experience. Such experiments would be to test the hypotheses developed in the previous three activities.

An additional direction for the research is the determining of the feasibility of the activity in other class situations, an exploration of the generalizability of the activity. We are cautious about the success of this activity in a different classroom situation at the present time. In our ME3110 class, learning essays represent just one facet of a multi-faceted doing and learning experience. In this context, students have many responsibilities, they are assessed in many ways, they have many opportunities for learning, and they have access to a wide audience who is interested in reacting to these learning essays. While we would be hesitant to advocate learning essays in class situations without these features, we do suspect that most students could and would benefit from being put in a situation where they were responsible for articulating their learning.

\section{ACKNOWLEDGMENTS}


The design of the Reflective Learner and the subsequent study during the Fall, 1996 quarter was supported by the Edutech Institute through a grant from the Woodruff Foundation. Work on the essay library was supported through NSF grant DM1-9420405. We would like to extend our sincere appreciation to the teaching team and all of the students of ME3110, without whom this research would not be possible.

\section{BIBLIOGRAPHY}

1. Dixon, J.R., New goals for Engineering Education. Mechanical Engineering, 1991. March: p. 56-62.

2. Dunbar, K., Concept Discovery in a Scientific Domain. Cognitive Science, 1993. 17: p. 397-434.

3. Chi, M.T.H. and M. Bassok, Learning from Examples via Self-Explanations, in Knowing, Learning, and Instruction: Essays in Honor of Robert Glaser, L. Resnick, Editor. 1989, Lawrence Erlbaum Associates: Hillsdale, NJ. p. 251-282.

4. Chi, M.T.H., et al., Eliciting Self-Explanations Improves Understanding. Cognitive Science, 1994. 18: p. 439477.

5. Kolb, D.A., Experiential Learning: Experience as the Source of Learning and Development. 1984, Englewood Cliffs, NJ: Prentice-Hall.

6. Kolodner, J., Case Based Reasoning. 1993, San Mateo, CA: Morgan Kaufman.

7. Bucciarelli, L.L., Reflective Practice in Engineering Design. Design Studies, 1984. 5(3): p. 185-190.

8. Bucciarelli, L.L., Designing Engineers. 1994, Cambridge: The MIT Press.

9. Schon, D.A., The Reflective Practioner: How Professionals Think in Action. 1983, New York: Basic Books. 374.

10. Turns, J.A. An Activity Framework for Fostering Reflection in Project-based Engineering Design Classes. in International Conference on the Learning Sciences. 1996. Evanston, IL: Association for the Advancement of Computing in Education.

11. Mistree, F., and Muster, F., Engineering Design as It Moves from an Art toward a Science: Its Impact on the Education Process. International Journal of Applied Education, 1988. 5(2): p. 239-246.

12. Newstetter, W. and J. Kolodner. Learning to Change the World: A Case Study of a Mechanical Engineering Design Course. in Frontiers in Education. 1995. Atlanta, GA:

13. Turns, J.A. I wish I had understood this at the beginning: Dilemmas in Teaching, Research, and Introduction of Technology into Engineering Design Courses. in Frontiers in Education. 1995.

\section{JENNIFER TURNS}

Jennifer Turns is a research assistant in the Center for Human-Machine Systems Research in Georgia Tech's Department of Industrial and Systems Engineering. She received her B.S. and M.S. in Systems Engineering from the University of Virginia. Her interests revolve around issues in engineering design education and include teaching engineering design through project- and problem-based approaches, studying the cognitive underpinnings of design activity, and developing technology to help teach, learn, and assess design education. She is a member of ASEE and AERA.

\section{WENDY NEWSTETTER}

Wendy Newstetter is research scientist with the Edutech Institute at the Georgia Institute of Technology. She received her B.A. degree from Colby College in Asian Studies and later her M.A. and Ph.D. degrees in Linguistics from Lancaster University. She is professionally interested in applications and implications of cognition to education and educational technology, specifically in engineering design education. She is a member of AERA. 


\section{JANET K. ALLEN}

Janet K. Allen is a senior research scientist in the Woodruff School of Mechanical Engineering at the Georgia Institute of Technology. She received her S.B. degree in life sciences from the Massachusetts Institute of Technology and her Ph.D. degree in Biophysics from the University of California at Berkeley. Her research interests include modeling design problems and processes, especially using constructs from living systems theory, and design education.

\section{FARROKH MISTREE}

Professor Farrokh Mistree's design experience spans mechanical, aeronautical, structural, industrial and software engineering. His research focus is on learning what happens when concurrent engineering principles are applied to the design, deployment, operation and support of open engineering systems. He is committed to developing a design pedagogy that is rooted in Decision-Based Design and adaptive action learning. It is in this context that he enjoys experimenting with ways in which design can be learned and taught. Professor Mistree is responsible for two books and over 180 technical publications. Since 1992 he is a Professor at Georgia Tech. He received his Bachelor of Technology with Honours from I.I.T. Kharagpur, India in 1968 and his M.S. and Ph.D. from the University of California, Berkeley in 1970 and 1974, respectively. He is a Fellow of ASME, a Senior Member of AIAA and a member of ASEE. URL http://www.srl.gatech.edu 